\title{
GFI1 promotes the proliferation and migration of esophageal squamous cell carcinoma cells through the inhibition of SOCS1 expression
}

\author{
YUNLONG HUANG $^{1 *}$, RAN RUAN $^{2 *}$, YANXIN FANG $^{1 *}$, KAIMING WU $^{1}$, \\ LONG YAO $^{1}$, RENQUAN ZHANG ${ }^{1}$ and WEI HE ${ }^{2}$ \\ ${ }^{1}$ Department of Thoracic Surgery, The First Affiliated Hospital of Anhui Medical University, Hefei, Anhui 230000; \\ ${ }^{2}$ Department of Immunology, School of Basic Medical Science, Anhui Medical University, Hefei, Anhui 230032, P.R. China
}

Received October 21, 2020; Accepted July 6, 2021

DOI: $10.3892 / \mathrm{ijmm} .2021 .5017$

\begin{abstract}
Growth factor-independent 1 (GFI1) has been reported to serve a vital role in hematopoietic development. However, the function and molecular mechanism of GFI1 in esophageal squamous cell carcinoma (ESCC) remains unknown. In the present study, the biological functions and the molecular mechanism of the effects of GFI1 in ESCC were analyzed. The results demonstrated that GFI1 expression levels were significantly upregulated in ESCC compared with those in normal esophageal tissues. Knockdown of GFI1 using small interfering RNA suppressed ESCC cell proliferation and migration. Furthermore, GFI1 enhanced STAT3 and NF- $\kappa$ B signaling by inhibiting the expression of suppressor of cytokine signaling 1 (SOCS1) in ESCC cells. Taken together, the results of the present study demonstrated that GFI1 promoted the proliferation and migration of ESCC cells via inhibition of SOCS1 expression. These results suggested that GFI1 may be a valuable target for ESCC therapy.
\end{abstract}

\section{Introduction}

Esophageal cancer (ESCA) is the 6th leading cause of cancer-associated mortality and one of the most common gastrointestinal tumors worldwide (1). ESCA includes

Correspondence to: Dr Wei He, Department of Immunology, School of Basic Medical Science, Anhui Medical University, 81 Mei Shan Road, Hefei, Anhui 230032, P.R. China

E-mail: weihe@ahmu.edu.cn

Professor Renquan Zhang, Department of Thoracic Surgery, The First Affiliated Hospital of Anhui Medical University, 218 Ji Xi Road, Hefei, Anhui 230000, P.R. China

E-mail: zhangrenquan@live.cn

*Contributed equally

Key words: growth factor-independent 1, esophageal squamous cell carcinoma, suppressor of cytokine signaling 1, STAT3 and NF- $\mathrm{B}$ signaling esophagus squamous cell carcinoma (ESCC) and esophageal adenocarcinoma (EAC) $(2,3)$. EAC is the most common type of ESCA in Western countries, whereas ESCC is the most common type in China, where it accounts for $>70 \%$ of cases of ESCA $(4,5)$. Although research into treatments for patients with ESCC has achieved significant progress, the 5 -year survival rate remains unfavorable due to the high rates of recurrence and metastasis $(4,6,7)$. Therefore, there is an urgent need to elucidate the molecular mechanism underlying ESCC progression.

As a zinc-finger transcriptional repressor, growth factor-independent 1 (GFI1) can bind histone deacetylases and inhibit transcription; its function was initially discovered due to its ability to serve as a cellular proto-oncogene in $\mathrm{T}$ cell lymphomas, where it promotes IL-2-independent growth (8). GFI1 has been reported to be involved in several types of cancer, including pancreatic ductal adenocarcinoma, cervical carcinoma and acute myeloid leukemia (AML), and it has also been found that GFI1 can control the transcription of suppressors of cytokine signaling (SOCS)1 (9-12). SOCS inhibit the JAK/STAT and NF- $\mathrm{B}$ pathways, among others $(13,14)$. Among the SOCS family of proteins, SOCS1 is the most potent inhibitor of proinflammatory cytokine signaling (15). In an ESCC xenograft mouse model, SOCS1 overexpression has been demonstrated to exhibit a potent antitumor effect against ESCC (16). Similarly, in a murine xenograft model, ectopic SOCS1 expression has been reported to improve radiosensitivity by inducing apoptosis and enhancing DNA damage following radiotherapy (17). Thus, SOCS1 serves an antitumor role in ESCC. It has been reported that GFI1 can bind directly to the SOCS1 promoter and suppress SOCS1 transcription in AML cells (12). Therefore, determining whether GFI1 is associated with ESCC through enhancing STAT3 and NF- $\kappa \mathrm{B}$ signaling activity via inhibiting SOCS1 may improve the current understanding of ESCC development.

The present study aimed to determine the expression of GFI1 in patients with ESCC and ESCC cells, as well as the functions of GFI1 in ESCC cells. Furthermore, the molecular mechanism underlying GFI1 activation in ESCC was analyzed. 


\section{Materials and methods}

Bioinformatics analysis. The mRNA expression levels of GFI1 from The Cancer Genome Atlas (TCGA; https://portal.gdc. cancer.gov/) were analyzed using UALCAN (http://ualcan. path.uab.edu) and OncoLnc (www.oncoLnc.org) databases. The databases from UALCAN contains the RNA-seq data (from TCGA), which includes the GFI1 expression levels from 184 tumor and 11 adjacent normal esophageal tissues. The survival curves based on GFI1 mRNA expression from OncoLnc were used to determine the effects of GFI1 expression levels on the survival of patients with ESCC. Kaplan-Meier analysis with the log-rank test was used for the survival analysis.

Clinical tissue samples. A total of 40 pairs of ESCC and adjacent normal esophageal tissues from patients with ESCC, including 22 women and 18 men (mean age, 60 years; aged from 46-75 years old), who received surgical treatment between March and December 2019, were collected at The First Affiliated Hospital of Anhui Medical University (Hefei, China) and were frozen in liquid nitrogen until required for RNA and protein extraction. The tumors were staged using the 8th edition of the American Joint Committee on Cancer Tumor-Node-Metastasis staging system (18). Patients were recruited if they had not received any radiotherapy or chemotherapy prior to surgery and had provided signed informed consent prior to inclusion. The present study was approved by the Ethics Committee of Anhui Medical University (approval no. 20190356). In addition, after radical esophagectomy, tumor tissues did not contain any necrotic area, and adjacent normal tissues were resected at $>5 \mathrm{~cm}$ from cancer tissue. The clinicopathological characteristics of the patients are summarized in Table I.

Cell culture. Normal esophageal epithelial cells (SHEE10) were obtained from The Cell Bank of Type Culture Collection of The Chinese Academy of Sciences, and four human ESCC cell lines (KYSE30, KYSE150, KYSE450 and KYSE510) were obtained from DSMZ-German Collection of Microorganisms and Cell Cultures GmbH. All cells were cultured in RPMI-1640 medium containing 10\% FBS (both Thermo Fisher Scientific, Inc.), streptomycin $(100 \mu \mathrm{g} / \mathrm{ml})$ and penicillin $(100 \mathrm{IU} / \mathrm{ml})$ at $37^{\circ} \mathrm{C}$ with $5 \% \mathrm{CO}_{2}$.

Cell transfection. KYSE 30 and KYSE150 cells $\left(3 \times 10^{5}\right.$ cells/well) were cultured in 6 -well plates. The cells were transfected with small interfering (si)RNA $(30 \mathrm{nM})$ or control siRNA $(30 \mathrm{nM})$ using Lipofectamine ${ }^{\circledR} 2000$ (Invitrogen; Thermo Fisher Scientific, Inc.) according to the manufacturer's protocol. After incubation at $37^{\circ} \mathrm{C}$ for $6 \mathrm{~h}$, the culture medium was changed. After transfection for $48 \mathrm{~h}$, the knockdown efficiency was assessed using reverse transcription-quantitative (RT-q) PCR and western blotting. siRNA targeting GFI1 (siGFI1) and SOCS1 (siSOCS1) were synthesized by GENERAL BIOL. The sequences of the siRNA were as follows: GFI1-siRNA, 5'-GCUCGGAGU UUGAGGACUU-3'; SOCS1-siRNA, 5'-GCAUCCGCGUGC ACUUUCAUU-3'; and control siRNA, 5'-UUCUCCGAA CGUGUCACGUTT-3'.
Table I. Summary of patient clinicopathological characteristics.

Patient characteristics

Sex

Female

Male

Age, year

$<60$

16

$\geq 60$

Differentiation

Well/moderate

Poor

Invasion

Absent

Present

Clinical stage ${ }^{\mathrm{a}}$

Early (I-II)

Advanced (III-IV)

Lymph node metastasis

Absent

Present

${ }^{a}$ American Joint Committee on Cancer/The Union for International Cancer Control Tumor-Node-Metastasis staging system (18).

Cell counting kit-8 (CCK-8) and colony formation assays. Cell proliferation was examined using CCK- 8 and colony formation assays. The CCK-8 assay was purchased from Dojindo Molecular Technologies, Inc. KYSE30 and KYSE150 cells $\left(1 \times 10^{3}\right.$ cells/well) were seeded into 96-well plates following transfection with siGFI1 or control siRNA for $48 \mathrm{~h}$. CCK- 8 solution $(10 \mu \mathrm{l})$ was added to each well at 24,48 or $72 \mathrm{~h}$, and the cells were further incubated at $37^{\circ} \mathrm{C}$ for $1.5 \mathrm{~h}$. Subsequently, the absorbance was measured at $450 \mathrm{~nm}$ using a microplate spectrometer (Thermo Fisher Scientific, Inc.).

For the colony formation assay, KYSE30 and KYSE150 cells $\left(2 \times 10^{3}\right.$ cells/well) were seeded in 6 -well plates, incubated overnight and subsequently transfected with siGFI1. Following 14-day culture, the cells were fixed with $4 \%$ formaldehyde at room temperature, washed three times with PBS and stained with trypan blue for $10 \mathrm{~min}$ at room temperature. The number of colonies (containing $\geq 50$ cells) were counted using a light microscope (magnification, x200; Olympus Corporation).

Cell migration and wound healing assay. For the cell migration assay, suspensions of transfected KYSE30 and KYSE150 cells $\left(1 \times 10^{4}\right.$ cells/well $)$ were re-suspended in FBS-free RPMI-1640 medium and added to the upper chamber of a Transwell chamber ( $8-\mu \mathrm{m}$ pore size; Corning, Inc.). RPMI-1640 medium supplemented with 10\% FBS (600 $\mu$ l) was added to the lower chamber. Following culturing for $24 \mathrm{~h}$ at $37^{\circ} \mathrm{C}$, the adherenT cells on the upper surface of the insert membrane were removed using cotton swabs, and the migrated cells were fixed with $4 \%$ formaldehyde at room temperature, washed three times with PBS and stained with trypan blue as 
Table II. Primer sequences used for reverse transcription-quantitative PCR.

\begin{tabular}{lll}
\hline Gene & Direction & Sequence (5'-3') \\
\hline GFI1 & Forward & GCAAGGCATTCAGCCAGAG \\
SOCS1 & Reverse & AAGGCAAAGGAGGAGCAA \\
& Forward & TTCGCCCTTAGCGTGAAGAT \\
Cyclin D1 & Reverse & GCTCGAAGAGGCAGTCGAA \\
& Forward & TGACCCCGCACGATTTCATT \\
Survivin & Reverse & CAGAGGGCAACGAAGGTCTG \\
& Forward & TTTTGATTCCCGGGCTTACCA \\
N-cadherin & Reverse & ACATTCACTGTGGAAGGCTCT \\
E-cadherin & Forward & CCTGAGGGATCAAAGCCTGG \\
& Reverse & ACATGTTGGGTGAAGGGGTG \\
Vimentin & Forward & AATTCCTGCCATTCTGGGGA \\
SOCS1 & Reverse & GGGCAGTAAGGGCTCTTTGA \\
& Forward & GTTTCCAAGCCTGACCTCAC \\
GAPDH & Reverse & GTCATTGTTCCGGTTGGCAG \\
& Forward & TTCGCCCTTAGCGTGAAGATGG \\
& Reverse & TAGTGCTCCAGCAGCTCGAAGA \\
& Forward & GTCTCCTCTGACTTCAACAGCG \\
& Reverse & ACCACCCTGTTGCTGTAGCCAA
\end{tabular}

GFI1, growth factor-independent 1; SOCS1, suppressor of cytokine signaling 1.

aforementioned. The migratory cells were imaged and counted under a light microscope (magnification, x200; Olympus Corporation).

For the wound healing assay, $1 \times 10^{6}$ transfected cells were seeded in 6-well plates for $48 \mathrm{~h}$ at $37^{\circ} \mathrm{C}$. The cell monolayer was scraped using a $200-\mu 1$ pipette tip when they reached $80-90 \%$ confluence, washed three times with PBS, and $2 \mathrm{ml}$ RPMI-1640 medium without FBS was added. The wound width was measured by capturing images under a microscope (magnification, x200; Olympus Corporation) at 0 and $24 \mathrm{~h}$.

$R T-q P C R$. Total RNA was isolated from clinical samples and cells using TRIzol ${ }^{\circledR}$ reagent (Invitrogen; Thermo Fisher Scientific, Inc.) and reverse-transcribed into cDNA using a HiScript III 1st Strand cDNA Synthesis kit (Vazyme Biotech Co., Ltd.) according to the manufacturer's protocol. qPCR was performed using LightCycler ${ }^{\circledR}$ FastStart DNA Master SYBR ${ }^{\circledR}$ Green I (Roche Diagnostics $\mathrm{GmbH}$ ) on a light Cycler 96 (Roche Diagnostics $\mathrm{GmbH}$ ), according to the manufacturer's instructions. The thermocycling conditions were as follows: Initial denaturation at $95^{\circ} \mathrm{C}$ for $30 \mathrm{sec}$, following by 40 cycles of denaturation at $95^{\circ} \mathrm{C}$ for $10 \mathrm{sec}$, annealing and elongation $60^{\circ} \mathrm{C}$ for $60 \mathrm{sec}$. GAPDH served as an internal control for gene expression, and the relative expression level was calculated using the $2^{-\Delta \Delta \mathrm{Cq}}$ method (19). The sequences of the primers used are listed in Table II.

Western blotting assay. Total protein was extracted from cells or tissues using RIPA lysis buffer (Beyotime Institute of Biotechnology), and the protein concentration was determined using a BCA protein assay kit (Beyotime Institute of Biotechnology). Total protein $(50 \mu \mathrm{g})$ was resolved using $10 \%$ SDS-PAGE and transferred to nitrocellulose membranes (Bio-Rad Laboratories, Inc.). The membranes were blocked with $5 \%$ non-fat milk for $1.5 \mathrm{~h}$ at room temperature, incubated with primary antibodies at $4^{\circ} \mathrm{C}$ overnight. The membranes were washed three times with PBST and then incubated with HRP-conjugated goat anti-mouse IgG (1:2,000; cat. no. SA00001-1; ProteinTech Group, Inc.) and goat anti-rabbit IgG (1:2,000; cat. no. 511203; Chengdu Zen Bioscience Co., Ltd.) secondary antibodies for $1 \mathrm{~h}$ at room temperature. Protein bands were visualized using an enhanced chemiluminescence detection system (Beyotime Institute of Biotechnology), and densitometry analysis was performed using ImageJ (v1.8.0, National Institutes of Health). Rabbit polyclonal antibodies against P65 (1:1,000; cat. no. 10745-1-AP) and mouse monoclonal antibodies against GAPDH (1:1,000; cat. no. 60004-1-Ig) were purchased from ProteinTech Group, Inc. Rabbit polyclonal antibodies against SOCS1 (1:1,000; cat. no. ab62584) and GFI1 (1:1,000; cat. no. ab21061) were obtained from Abcam. Rabbit polyclonal antibodies against phosphorylated (p)-p65 (1:1,000; cat. no. 310012) were obtained from Chengdu Zen Bioscience Co., Ltd. Rabbit monoclonal antibodies against STAT3 (1:1,000; cat. no. 4904S) and p-STAT3 (1:1,000; cat. no. 4113S) were purchased from Cell Signaling Technology, Inc.

Immunohistochemistry (IHC). ESCC and paired normal tissues were embedded in paraffin, fixed in $4 \%$ paraformaldehyde at room temperature for 2 days and cut into $5-\mu \mathrm{m}$ sections for IHC analysis. IHC staining was performed by Wuhan Servicebio Technology Co., Ltd. The sections were examined, 
A Expression of GFI1 in ESCA based on Sample types

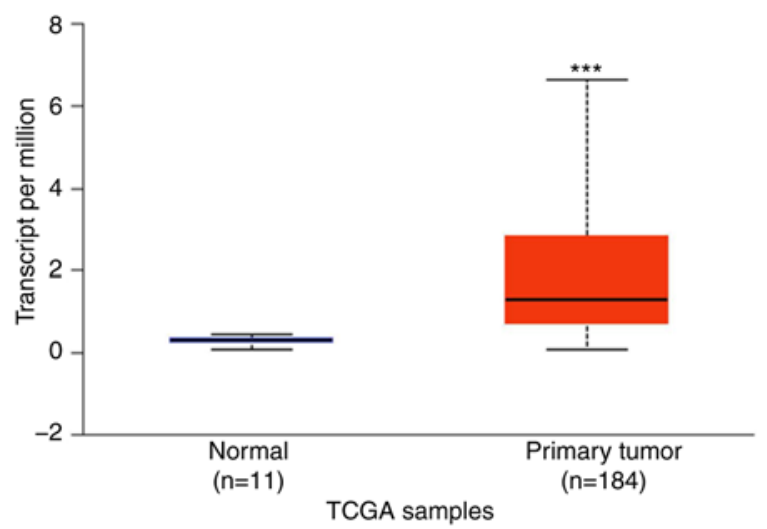

C Expression of GFI1 in ESCA based on patient's age

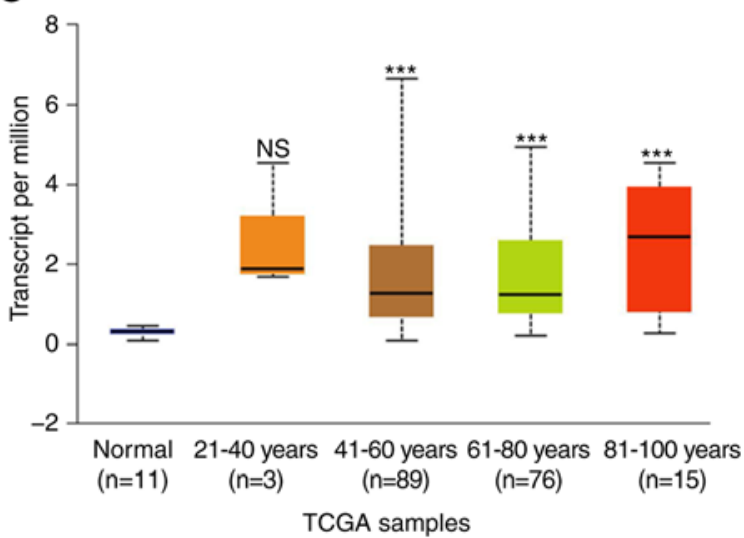

E

Expression of GFI1 in ESCA based on individual

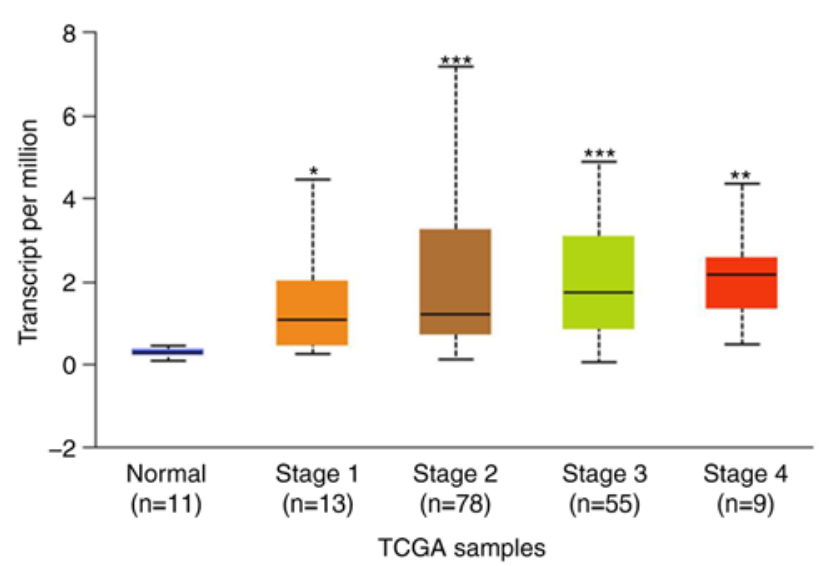

B

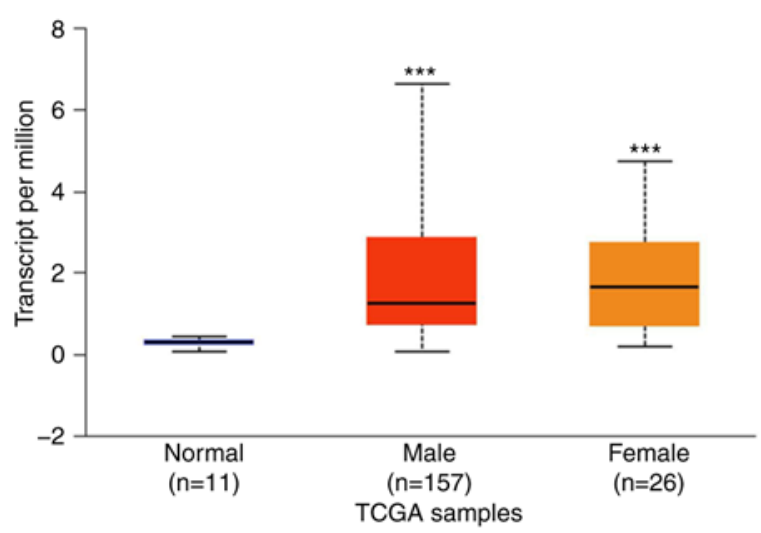

D

Expression of GFI1 in ESCA based on patient's

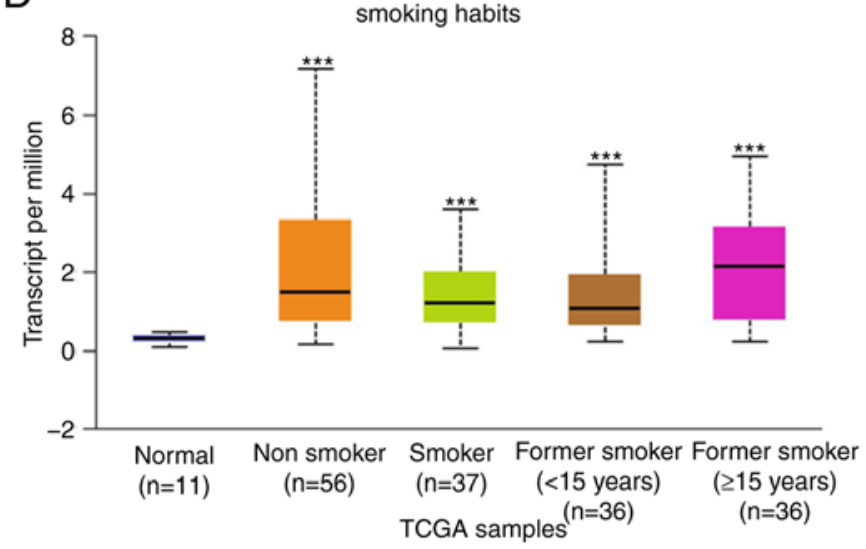

F Expression of GFI1 in ESCA based on nodal metastasis status

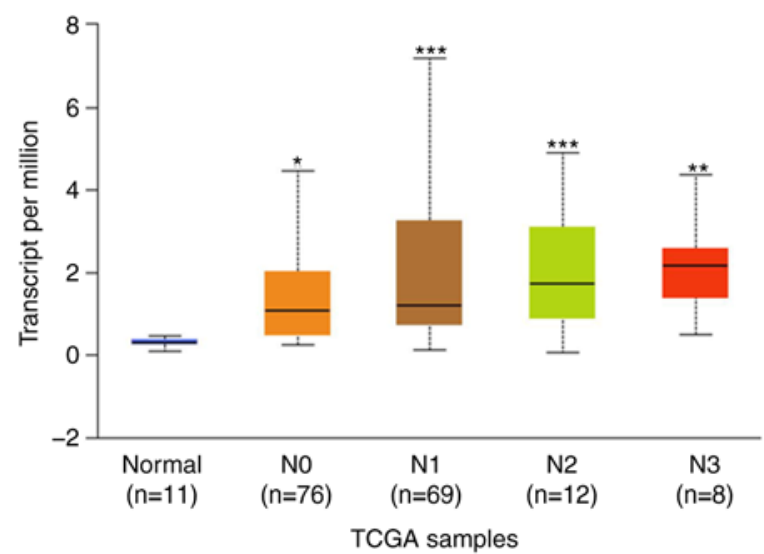

Figure 1. GFI1 mRNA expression is upregulated in ESCA tissues in TCGA. (A) GFI1 expression levels were significantly higher in ESCA tissues compared with those in normal tissues. (B-F) GFI1 expression levels in patients grouped by (B) sex, (C) age, (D) smoking status, (E) cancer stage and (F) nodal metastasis status of ESCA. ${ }^{*} \mathrm{P}<0.05,{ }^{* *} \mathrm{P}<0.01$ and ${ }^{* * *} \mathrm{P}<0.001$ vs. normal. GFI1, growth factor-independent 1 ; TCGA, The Cancer Genome Atlas; ESCA, esophageal cancer; $\mathrm{N}$, node.

and images were captured using a microscope (magnification, $\mathrm{x} 200$; Olympus Corporation) in five random fields of view per sample.

Luciferase reporter assay. KYSE30 and KYSE150 cells (2x10 $/$ well) were seeded and cultured in 12-well plates overnight and co-transfected with an $\mathrm{NF}-\kappa \mathrm{B}$ reporter plasmid ( $1 \mu \mathrm{g} / \mathrm{well}$; cat. no. D2206; Beyotime Institute of Biotechnology) and siGFI1 (30 nM), siSOCS1 (30 nM) or siCtrl (30 nM) using Lipofectamine ${ }^{\circledR} 2000$ according to the manufacturer's instructions. After incubation at $37^{\circ} \mathrm{C}$ for $6 \mathrm{~h}$, the culture medium was changed. At $48 \mathrm{~h}$ post-transfection, cell samples were lysed using Firefly Luciferase Reporter Gene Assay Cell Lysis Buffer (cat. no. RG126S; Beyotime Institute of Biotechnology). After brief centrifugation at $13,778 \mathrm{x} \mathrm{g}$ for $20 \mathrm{~min}, 10 \mu \mathrm{l}$ aliquot of the supernatant was assayed using a Luciferase Assay kit (Promega Corporation), and the same amount of supernatant was used to measure the concentration of total protein using a BCA protein assay (cat. no. P0012S; Beyotime Institute of Biotechnology). The 
A

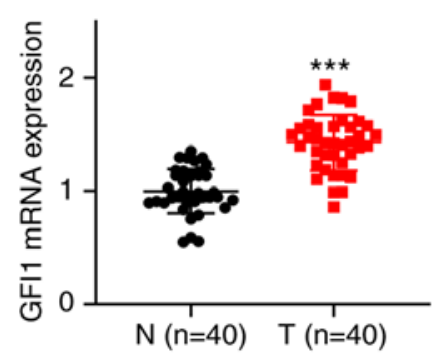

B
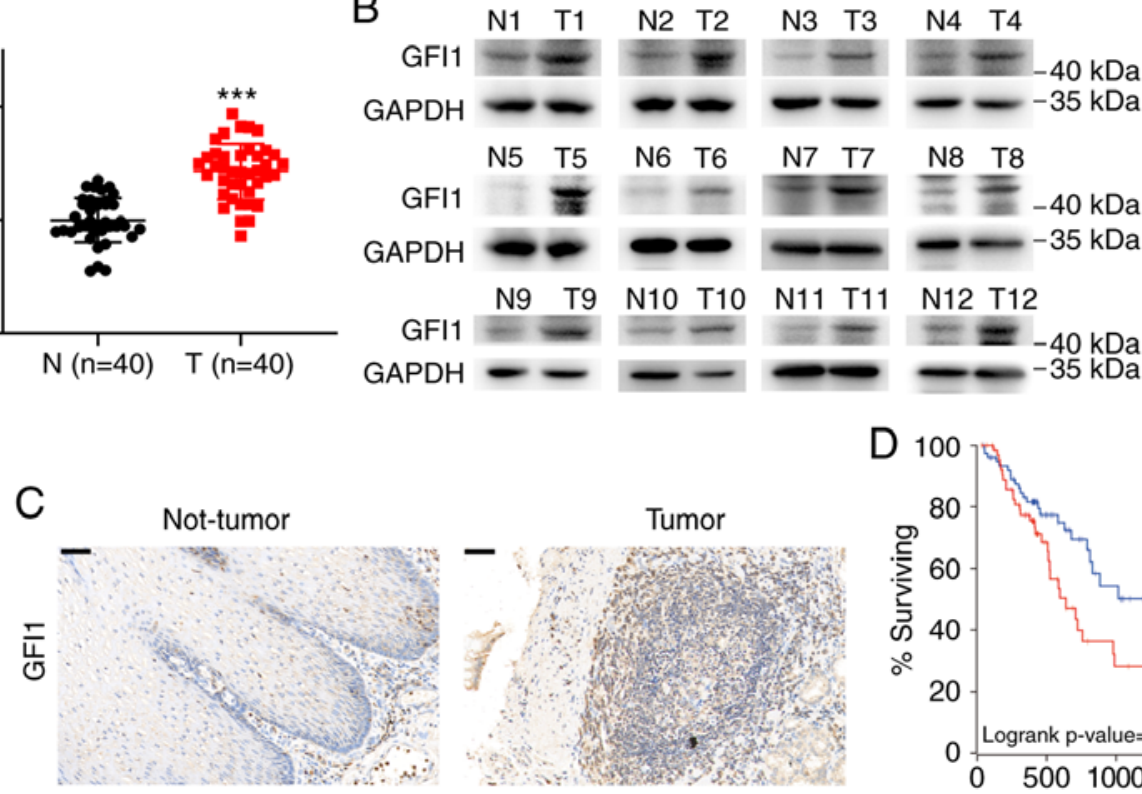

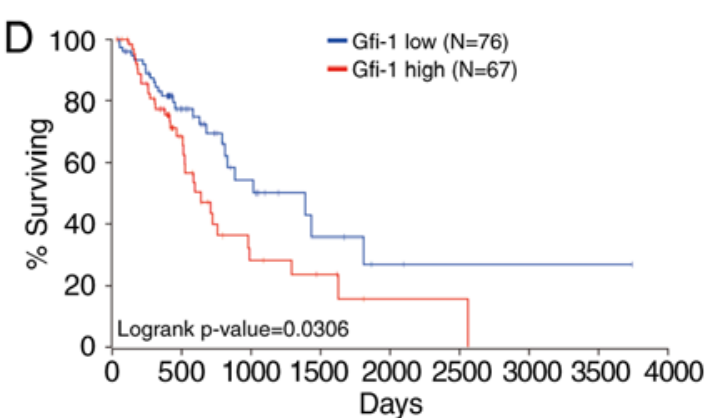

Figure 2. GFI1 expression is upregulated in ESCC tissues. (A) mRNA and (B) protein expression levels of GFI1 in tissues of patients with ESCC were examined using reverse transcription-quantitative PCR $(n=40)$ and western blotting $(n=12)$. (C) Immunohistochemical staining of GFI1 in ESCC and normal tissues. Scale bar, $50 \mu \mathrm{m}$. (D) Kaplan-Meier overall survival analysis of patients with esophageal cancer from the OncoLnc database stratified by median GFI1 mRNA expression. ${ }^{* * *} \mathrm{P}<0.001$ vs. N. GFI1, growth factor-independent 1; ESCC, esophageal squamous cell carcinoma; N, normal; T, tumor.

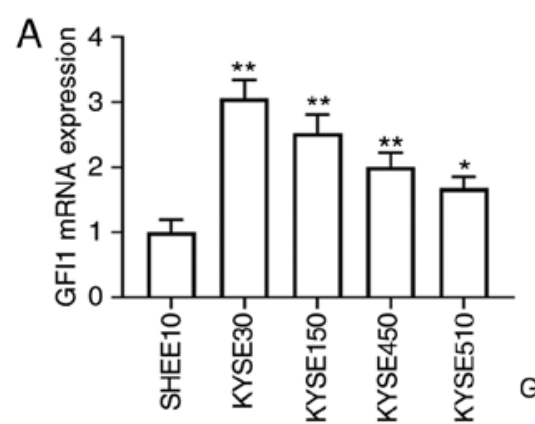

B

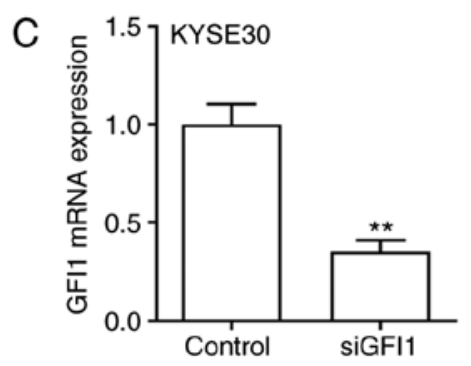

E

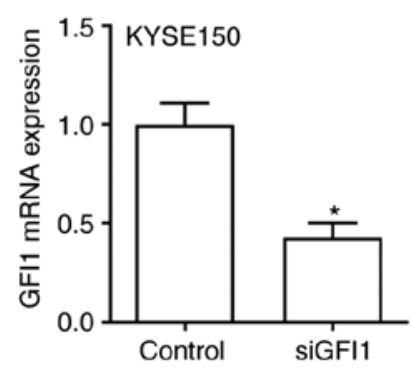

D

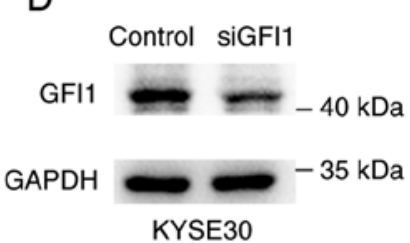

F

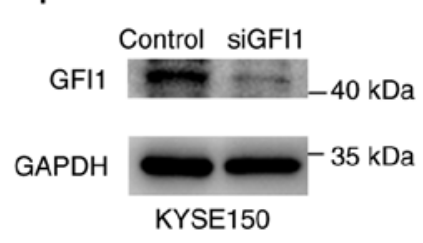

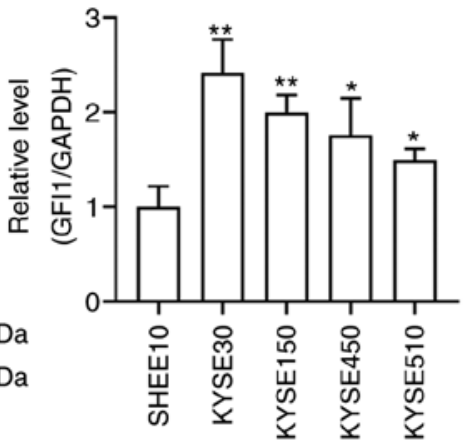
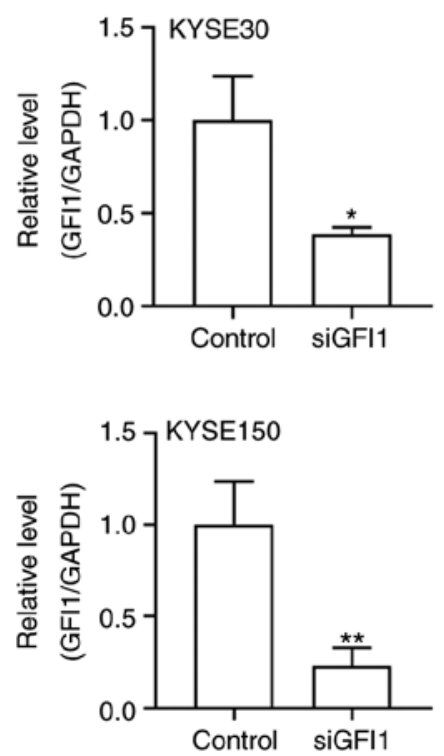

Figure 3. Efficiency of GFI1 knockdown in ESCC cells using siRNA. (A) mRNA and (B) protein expression levels of GFI1 in the SHEE10 normal esophageal epithelial cells and four ESCC cell lines: KYSE30, KYSE150, KYSE450 and KYSE510. (C-F) GFI1-siRNA was transfected into the KYSE30 and KYSE150 ESCC cell lines. The mRNA and protein expression levels of GFI1 in ESCC cell lines were detected using reverse transcription-quantitative PCR and western blotting. ${ }^{*} \mathrm{P}<0.05$ and ${ }^{* *} \mathrm{P}<0.01$ vs. SHEE10 or control. siRNA/si, small interfering RNA; GFI1, growth factor-independent 1 ; ESCC, esophageal squamous cell carcinoma. 
A

Control siGFI1
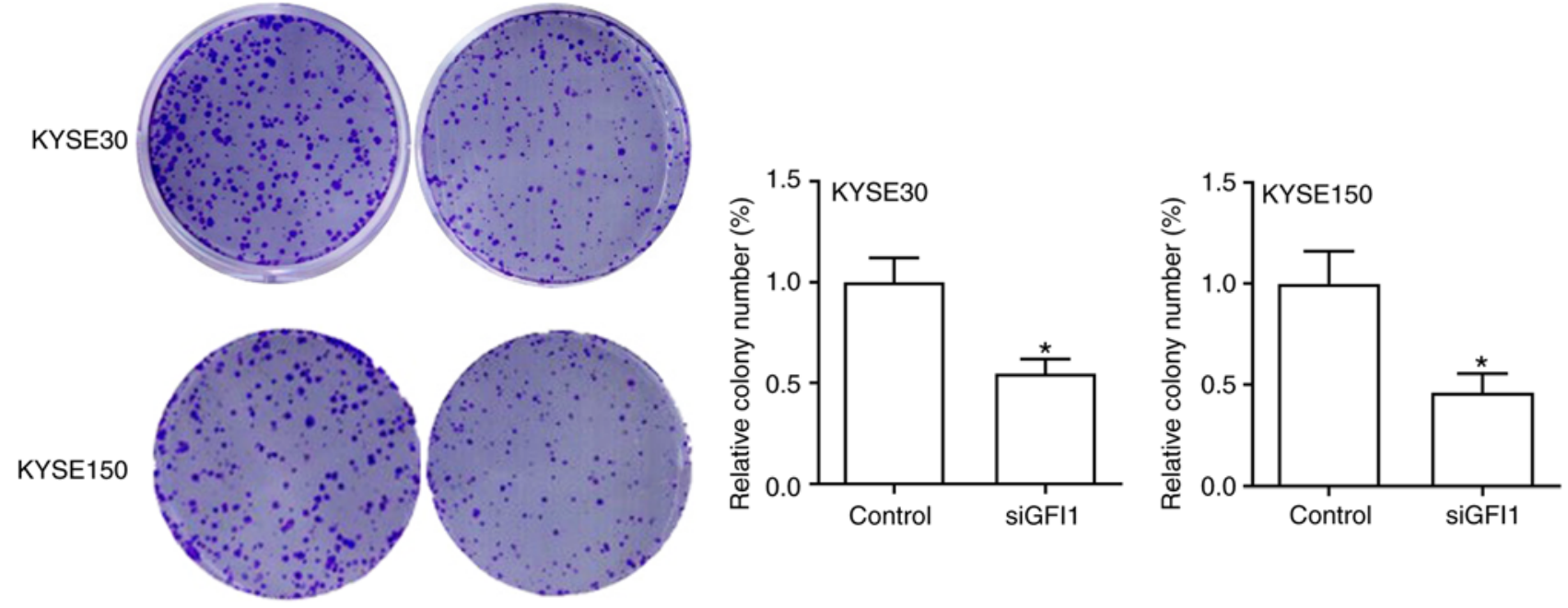

B
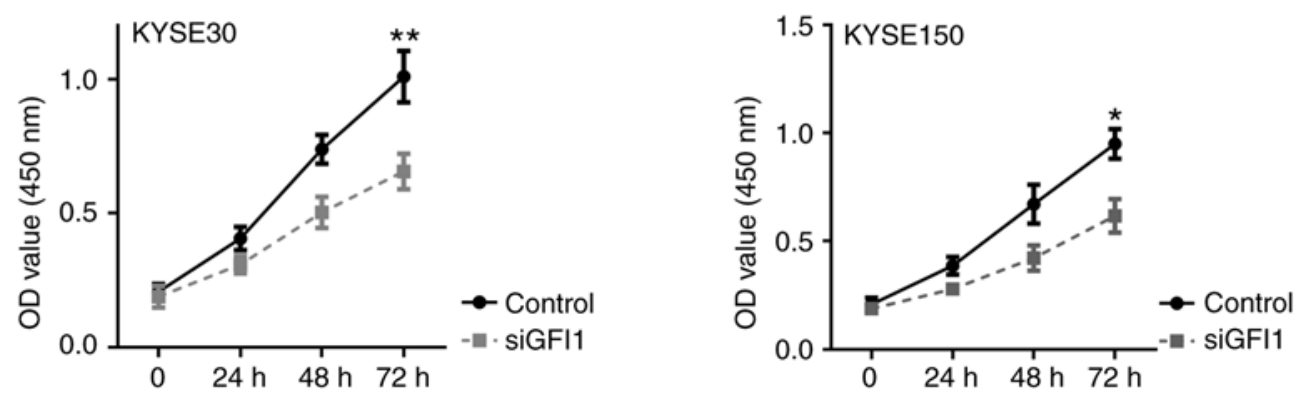

Figure 4. GFI1 knockdown decreases the proliferation of ESCC cell lines. (A) Colony formation assays were performed using the siGFI1-transfected ESCC cells. (B) Cell proliferation was assessed in the siGFI1-transfected ESCC cell lines (KYSE30 and KYSE150) using a Cell Counting Kit-8 assay. ${ }^{*}<0.05$ and ${ }^{* *} \mathrm{P}<0.01$ vs. control. si, small interfering RNA; GFI1, growth factor-independent 1; ESCC, esophageal squamous cell carcinoma; OD, optical density.

luciferase activity was normalized against the concentration of total protein.

Statistical analysis. All experiments were performed in triplicate. Statistical analysis was performed using GraphPad Prism 8 (GraphPad Software, Inc.), and data are presented as the mean \pm SEM. Statistical differences between groups were compared using a paired or unpaired Student's t-test as appropriate, a one-way ANOVA with Tukey's post hoc test. $\mathrm{P}<0.05$ was considered to indicate a statistically significant difference.

\section{Results}

GFII expression is upregulated in ESCC tissues. The expression levels of GFI1 in ESCA were analyzed using data obtained from TCGA using the UALCAN platform. As presented in Fig. 1A, GFI1 expression levels were significantly upregulated in ESCA tissues compared with those in normal tissues. Furthermore, a statistically significant association between the mRNA levels of GFI1 and the clinicopathological features of ESCA were observed based on the UALCAN platform. GFI1 mRNA expression levels were increased in ESCA regardless of sex, patient age (20-40, 41-60, 61-80 and 81-100 years old), smoking status [non-smoker, smoker, short-term former smoker ( $<15$ years) and long-term former smoker ( $\geq 15$ years)], cancer stages (S1-4) and nodal metastasis status (N0-4) compared with those in normal tissues (Fig. 1B-F). These results suggested that GFI1 was upregulated in ESCA and may affect ESCA progression.

Next, the potential functions of GFI1 in ESCC were explored in the present study. The mRNA expression levels of GFI1 in 40 pairs of ESCC and adjacent normal tissues were assessed using RT-qPCR. The results demonstrated that the mRNA levels of GFI1 were increased in ESCC tissues compared with those in the normal adjacent tissues (Fig. 2A). Western blotting also revealed that GFI1 protein levels were significantly upregulated in ESCC compared with those in normal tissues (Fig. 2B). Similar to the results of western blotting, IHC analysis of samples from ESCC and matched adjacent tissues demonstrated that high GFI1 expression was observed in ESCC tissues (Fig. 2C). Kaplan-Meier survival analysis using the OncoLnc online tool suggested that patients with ESCA that exhibited higher than the median expression levels of GFI1 had shorter overall survival times compared with those observed in patients with low GFI1 levels (Fig. 2D).

Together, these results indicated that GFI1 was upregulated in ESCC tissues and associated with a poor prognosis, suggesting that GFI1 may promote the progression of ESCC.

GFII is highly expressed in ESCC cell lines and is knocked down by siRNA. The expression levels of GFI1 in SHEE10 and four ESCC cell lines (KYSE30, KYSE150, KYSE450 and KYSE510) were assessed, and the results demonstrated 
A
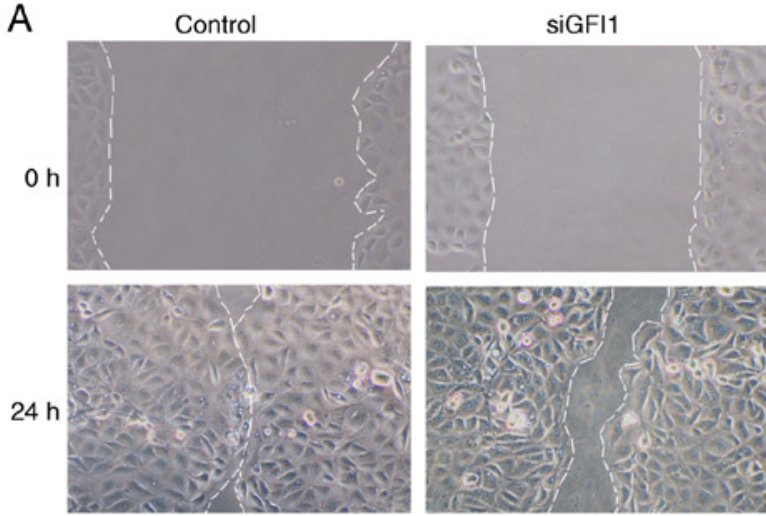

KYSE30
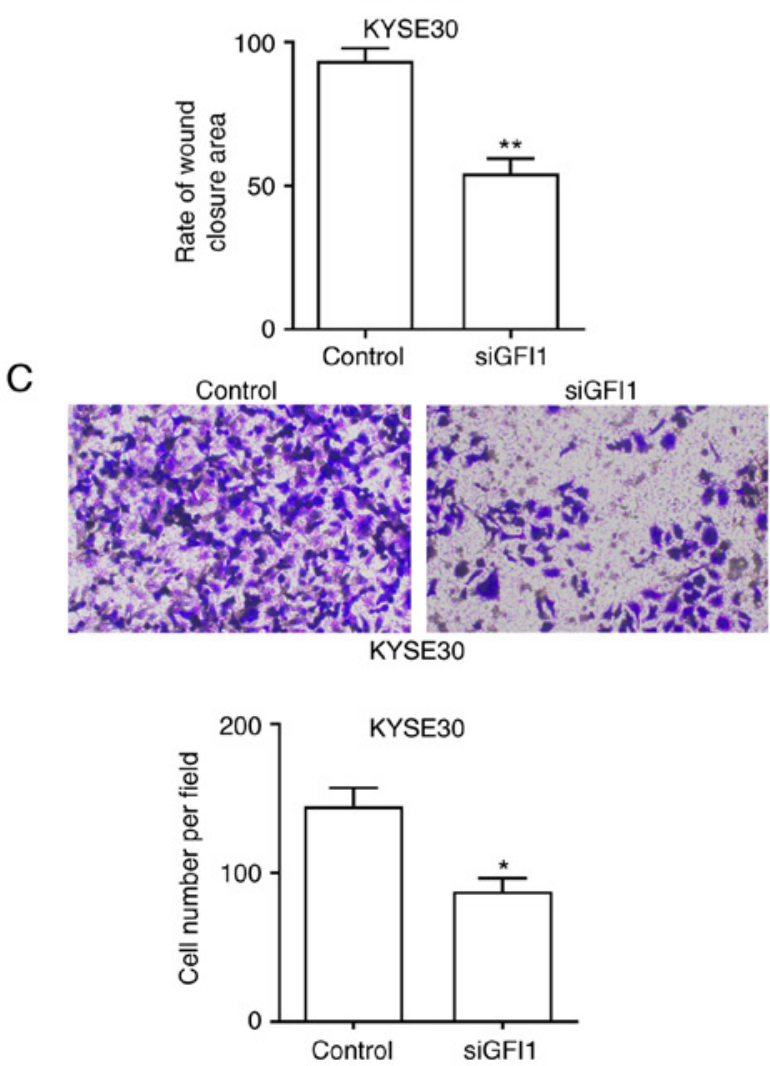

B
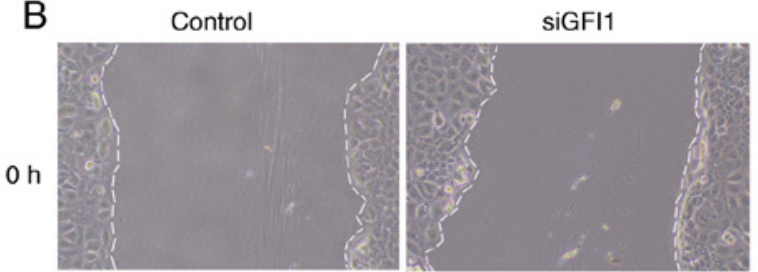

$24 \mathrm{~h}$
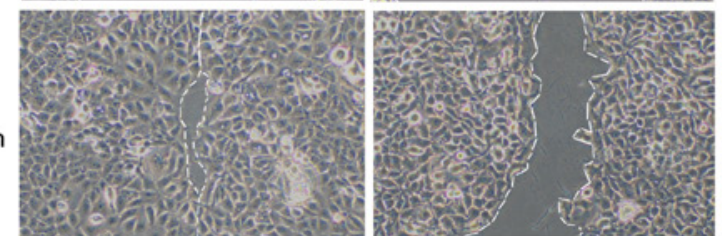

KYSE150

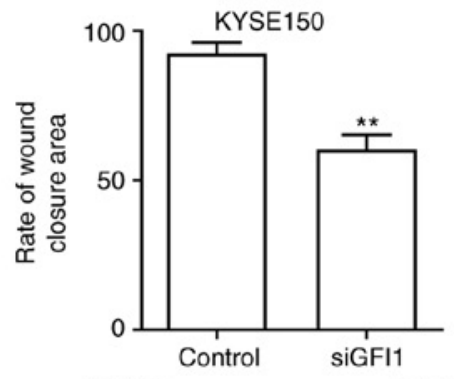

D
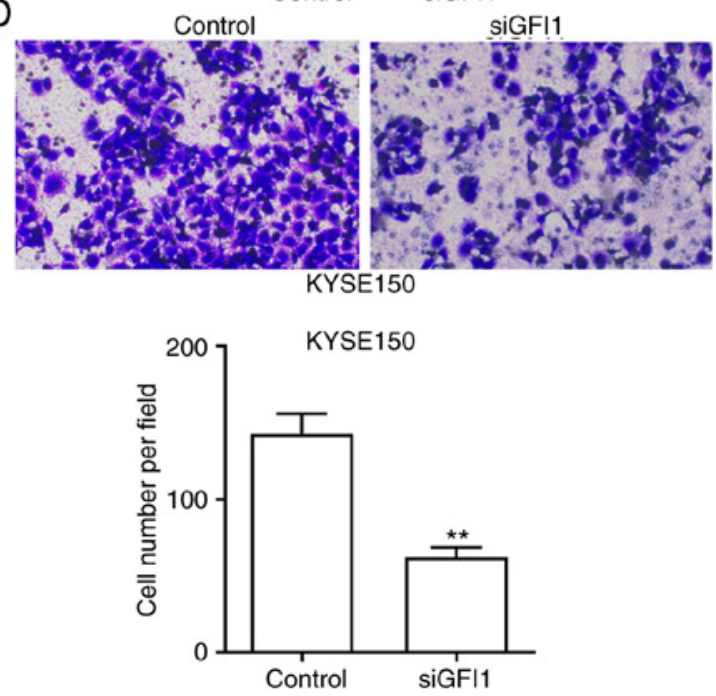

Figure 5. GFI1 knockdown reduces the migration of esophageal squamous cell carcinoma cells. (A and B) Wound healing and (C and D) Transwell assays were used to determine the effects of GFI1 knockdown on KYSE30 and KYSE150 cell migration. Magnification, $\mathrm{x} 200$. $^{*} \mathrm{P}<0.05$ and ${ }^{* *} \mathrm{P}<0.01$ vs. control. si, small interfering RNA; GFI1, growth factor-independent 1.

that the mRNA and protein levels of GFI1 were significantly increased in ESCC cells compared with those in the normal esophageal cell line (Fig. 3A and B). Subsequently, KYSE30 and KYSE150 cells, which exhibited the highest levels of endogenous GFI1 expression, were transfected with siGFI1. As presented in Fig. 3C-F, both cell lines transfected with siGFI1 exhibited lower GFI1 mRNA and protein expression levels compared with those in the control group. Thus, KYSE30 and KYSE150 cells were both successfully transfected.

GFI1 knockdown suppresses the proliferation of ESCC cells. The effects of GFI1 on cell proliferation in vitro were next assessed. The results of colony formation and CCK-8 assays demonstrated that GFI1 knockdown significantly reduced the proliferative rates of KYSE30 and KYSE150 cells compared with those of the control cells (Fig. 4A and B). In addition, the expression levels of the cell cycle-associated genes cyclin D1 and survivin were assessed using RT-qPCR. As presented in Fig. S1A, knockdown of GFI1 significantly downregulated the levels of cyclin D1 and survivin in both cell lines compared with those in the respective control groups. These results suggested that GFI1 promoted ESCC cell proliferation.

GFII knockdown reduces the migration of ESCC cells. To investigate the function of GFI1 on ESCC cell migratory ability, wound healing and Transwell assays were performed. The wound healing assay results demonstrated that the tumor cell migration was significantly reduced in both cell lines transfected with siGFI1 compared with that in the control cells (Fig. 5A and B). In the Transwell assays, the number of cells that had migrated through the membrane was reduced in KYSE30 and KYSE150 cells transfected with siGFI1 compared with 
A
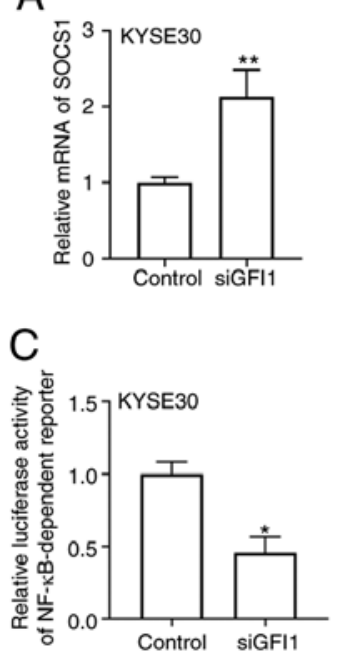
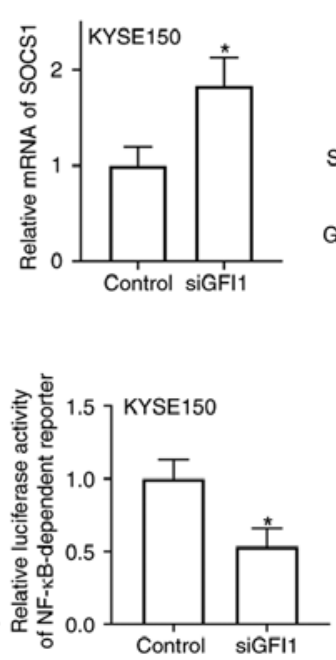

B
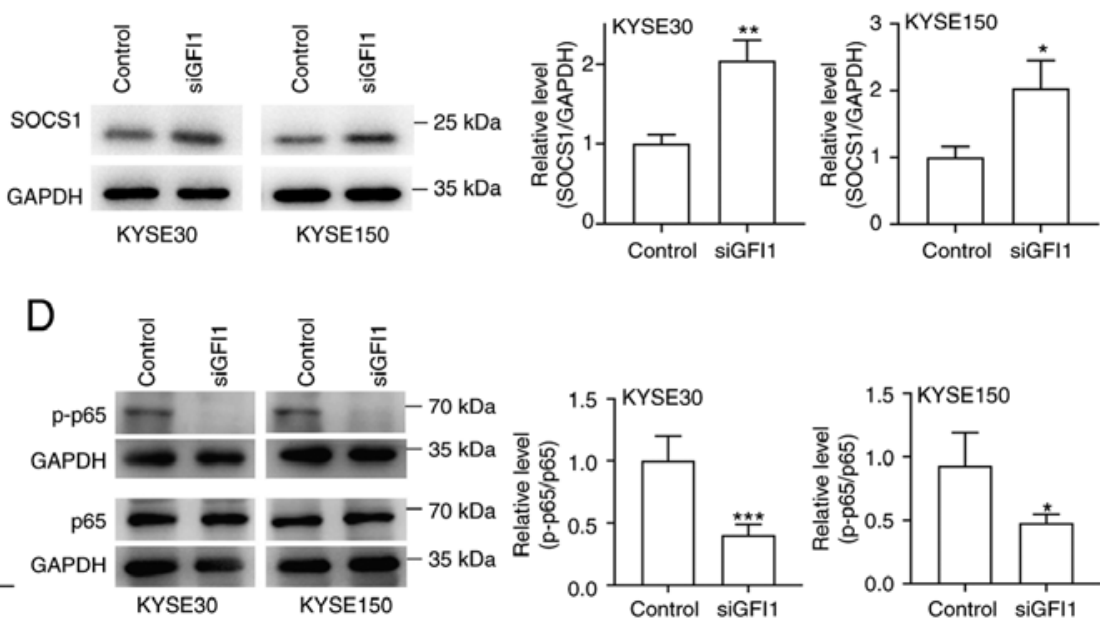

$\mathrm{E}$

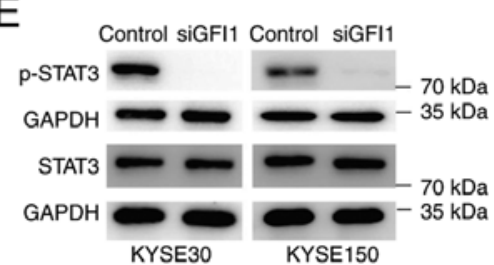

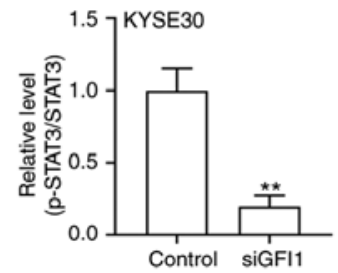

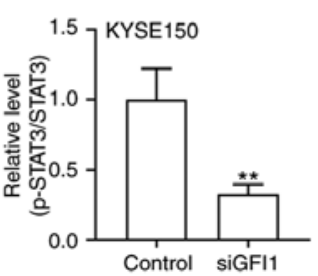

Figure 6. GFI1 enhances NF- $\mathrm{B}$ and STAT3 activity by inhibiting SOCS1 expression in esophageal squamous cell carcinoma cell lines. (A and B) siGFI1 was transfected into KYSE30 and KYSE150 cells. (A) mRNA and (B) protein expression levels of SOCS1 were examined using reverse transcription-quantitative PCR and western blotting, respectively. (C) NF-кB activity, (D) p-p65 and (E) p-STAT3 protein levels were analyzed in KYSE30/KYSE150 cells following transfection with siGFI1. ${ }^{*} \mathrm{P}<0.05,{ }^{* *} \mathrm{P}<0.01$ and ${ }^{* * *} \mathrm{P}<0.001$ vs. control. si, small interfering RNA; GFI1, growth factor-independent 1 ; SOCS1, suppressor of cytokine signaling 1 ; p-, phosphorylated.

those in the respective control groups (Fig. 5C and D). In addition, the expression levels of epithelial and mesenchymal markers E-cadherin, $\mathrm{N}$-cadherin and vimentin in KYSE30 and KYSE150 cell lines treated with siGFI1 were determined. As demonstrated in Fig. S1B, the mRNA expression levels of E-cadherin were increased, and the levels of $\mathrm{N}$-cadherin and Vimentin were reduced compared with those in the control cells. Together, these results indicated that GFI1 promoted ESCC cell migration and may induce the EMT progression.

GFI1 knockdown inhibits STAT3 and NF- $\kappa$ B signaling via upregulation of SOCS1 expression. Whether GFI1 regulated the STAT3 and NF- $\kappa \mathrm{B}$ signaling pathways by inhibiting SOCS1 expression in ESCC cell lines was determined in the present study. As demonstrated in Fig. 6A and B, GFI1 knockdown in KYSE30 and KYSE150 cells increased SOCS1 mRNA and protein levels compared with those in the control cells. Additionally, NF- $\kappa \mathrm{B}$ activity was reduced in both cell lines following knockdown of GFI1 compared with that in the control groups (Fig. 6C). When the NF-kB signaling pathway is activated, p65 is rapidly phosphorylated and translocates to the nucleus (20); when GFI1 expression was knocked down in KYSE30 and KYSE150 cells, the levels of p-p65 were notably decreased compared with those in the control cells (Fig. 6D). In addition, as presented in Fig. 6E, knockdown of GFI1 inhibited STAT3 phosphorylation in both cell lines.

To analyze whether SOCS1 inhibition was required for the GFI1-mediated increases in the proliferative and migratory capacities of ESCC cells, the present study transfected siSOCS1 into KYSE30 and KYSE150 cells. The transfection efficiency was confirmed by RT-qPCR and Western blotting analyses, and the results demonstrated that both cell lines transfected with siSOCS1 exhibited lower SOCS1 mRNA and protein expression levels compared with those in the control groups (Fig. S2A-D). Subsequently, SOCS1 expression was knocked down in ESCC cells following GFI1 knockdown. Colony formation and Transwell migration assay results revealed that knockdown of SOCS1 compensated for the loss of proliferation and migration induced by GFI1 knockdown (Fig. 7A and B). In addition, SOCS1 knockdown attenuated the reduction in NF- $\kappa$ B activity and the reduction in p-p65 and p-STAT3 levels (Fig. 7C-H). Taken together, these results demonstrated that GFI1 may promote ESCC cell proliferation via inhibiting SOCS1 expression and enhancing NF- $\mathrm{kB}$ and STAT5 activity (Fig. 8).

\section{Discussion}

Although a number of improvements have been achieved in the treatment of ESCC, surgical resection remains the most effective treatment for patients with ESCC (21). However, the 5-year overall survival rates remains poor at an estimated $15-20 \%$, and $43 \sim 53 \%$ of patients who undergo surgery experience local recurrence and/or distant metastasis $(22,23)$. Therefore, elucidating the molecular mechanisms underlying the development and progression of ESCC, and identifying novel therapeutic targets may improve ESCC treatment. 

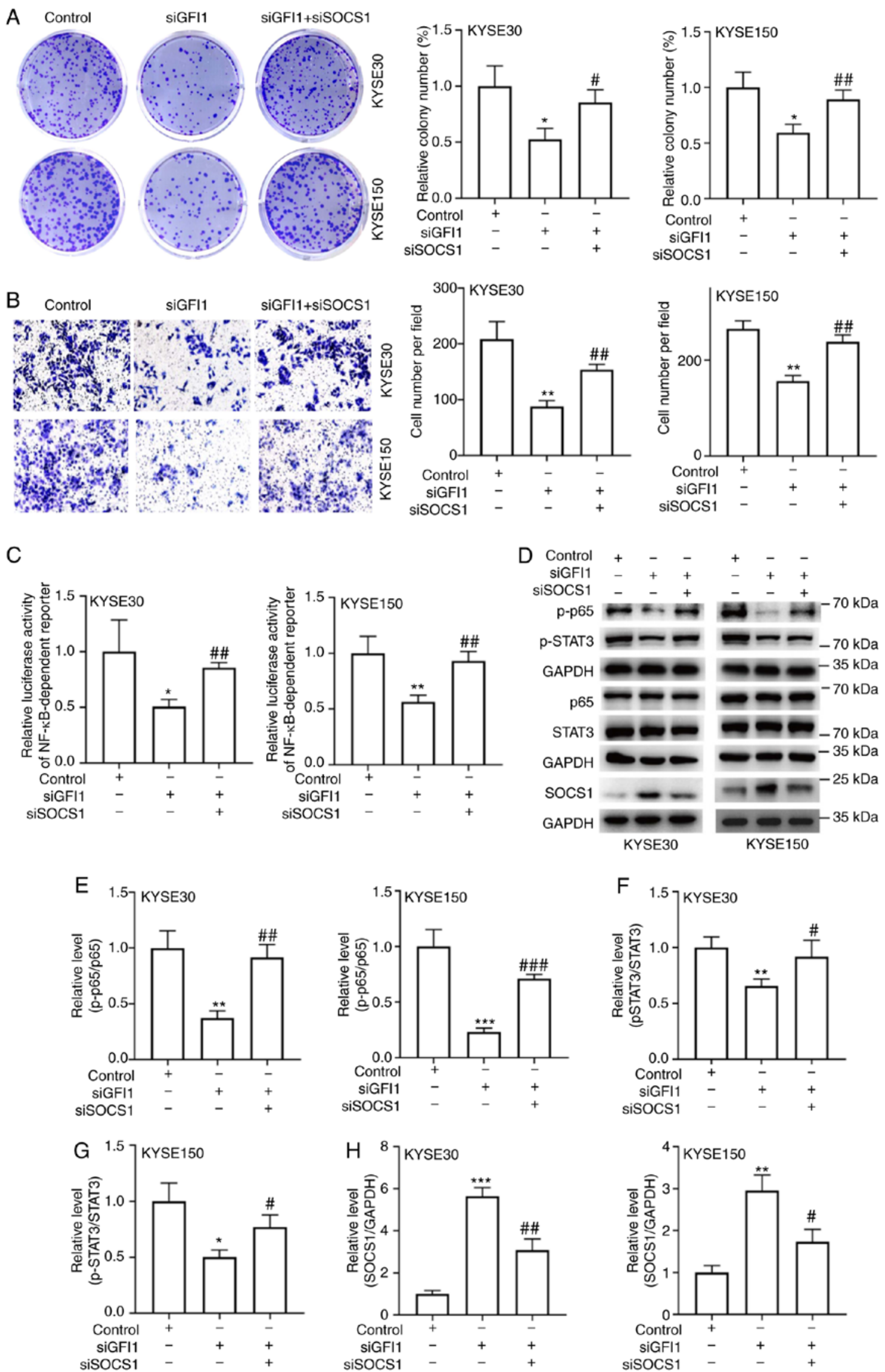

Figure 7. SOCS1 inhibits the increase in esophageal squamous cell carcinoma cell proliferation and migration induced by GFI1. (A-H) siSOCS1 was transfected into the GFI1-knockdown KYSE30 and KYSE150 cells. (A) Colony formation assays were performed on the double transfected cells. (B) Cell migration was determined using Transwell assays. (C) NF-kB activity, (D) p-p65, p-STAT3 and SOCS1 protein levels were analyzed. (E-G) Ratio of p-p65 to p65 and STAT3 to p-STAT3, as well as $(\mathrm{H})$ the semi-quantification of SOCS1 protein expression were determined using ImageJ. Magnification, $\mathrm{x} 200 .{ }^{*} \mathrm{P}<0.05,{ }^{* *} \mathrm{P}<0.01$ ${ }_{* * * *} \mathrm{P}<0.001$ vs. control; ${ }^{\#} \mathrm{P}<0.05,{ }^{\# \#} \mathrm{P}<0.01$ and ${ }^{\# \#} \mathrm{P}<0.001$ vs. siGFI1. SOCS1, suppressor of cytokine signaling 1; si, small interfering RNA; GFI1, growth factor-independent $1 ;$ p-, phosphorylated. 


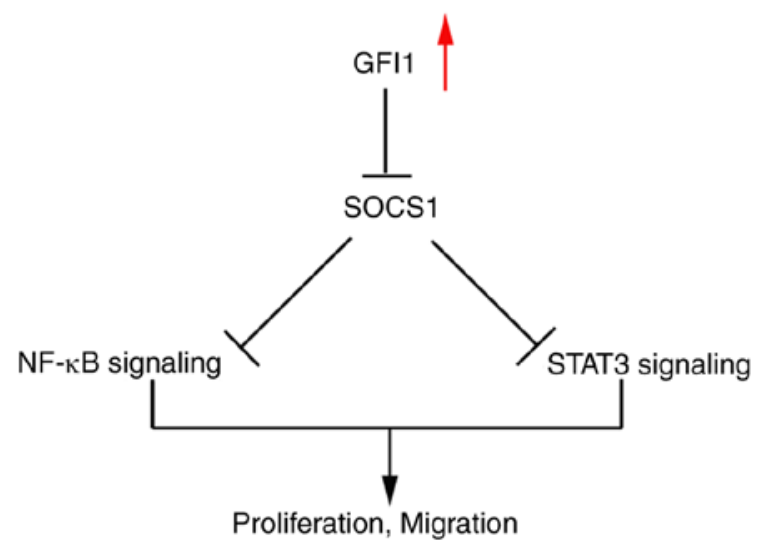

Figure 8. Regulatory model of the role of GFI1 in ESCC progression. The results of the present study demonstrated that the upregulation of GFI1 promoted ESCC proliferation and migration via inhibition of SOCS1 expression, leading to the activation of the NF- $\mathrm{kB}$ and STAT3 pathways. GFI1, growth factor-independent 1; ESCC, esophageal squamous cell carcinoma; SOCS1, suppressor of cytokine signaling 1.

Previous studies have demonstrated that GFI1 not only regulates the development of multiple hematopoietic lineages, including macrophages, dendritic cells, granulocytes, as well as $\mathrm{T}$ and $\mathrm{B}$ cells, but it also participates in the self-renewal and survival of hematopoietic stem cells $(24,25)$. GFI1-knockout mice exhibit defects in $\mathrm{B}$ cell, $\mathrm{T}$ cell and neutrophil differentiation, as well as in the response of mature $\mathrm{B}$ and $\mathrm{T}$ cells to antigens (26). In addition, GFI1 inhibits T cell death induced by cultivation of IL-2-dependent T cell lines in IL-2-deficient media by repressing Bax expression (27). Although GFI1 has been reported to be involved in the development and progression of cervical cancer and lymphomas, its functions in ESCC remain unclear. In the present study, GFI1 expression levels were markedly upregulated in ESCC tissues compared with those in adjacent normal tissues, and GFI1 knockdown reduced cell proliferation and migration of ESCC cells.

As an inhibitor of DNA binding, GFI1 targets a range of proteins in various types of cells, including STAT5B, MCL1 apoptosis regulator, BCL2 family member, RUNX family transcription factor 2, suppressor of cytokine signaling 1 and F-box and WD repeat domain-containing $7(9,12,28,29)$. SOCS1 was originally identified as a suppressor of cytokine signaling, and belongs to the SOCS family of proteins (30). SOCS1 inhibits proliferation signals modulated by various oncogenes (CDK2, CyclinD1 and STATs) in cancer development (31). Previous studies have reported that aberrant downregulation of SOCS1 is involved in the clinical progression of a number of types of cancer, including hepatocellular carcinoma, bladder and triple-negative breast cancer (32-34). In the present study, the results demonstrated that GFI1 knockdown increased the levels of SOCS1 expression compared with those in the control cells. An increasing number of studies have reported that SOCS1 targets several signaling pathways, including the JAK/STAT, MAPK and NF- $\kappa B$ pathways $(15,35,36)$. The STAT3 and NF- $\kappa B$ signaling pathways are two vital intracellular pathways that serve key roles in modulating cell differentiation, proliferation, migration and metabolism $(37,38)$. These pathways are frequently overactivated in various types of cancer, including colorectal, non-small lung and breast cancer, and have been reported to contribute to tumor progression and drug resistance (39-41). Previous studies have demonstrated that the STAT3 and NF- $\mathrm{kB}$ pathways are aberrantly activated during ESCC development $(17,42,43)$. However, whether both pathways are associated with the role of GFI1 in ESCC remains unknown. The results of the present study demonstrated that knocking down GFI1 expression significantly reduced SOCS1 expression levels and further reduced the levels of p-STAT3 as well as NF- $\kappa \mathrm{B}$ activity.

The major limitation of the present study was that the data were obtained from both EAC and ESCC, since hypothesized from the EAC results that GFI1 may also be relevant in ESCC.

In conclusion, the results of the present study demonstrated that GFI1 was significantly upregulated in ESCC tissues and cells compared with those in normal esophageal tissues and cells. Knockdown of GFI1 reduced ESCC cell proliferation and migration by decreasing SOCS1 expression levels, which occurred via the regulation of the STAT3 and NF- $\mathrm{KB}$ signaling pathways. Thus, GFI1 may serve as a potential therapeutic target for the treatment of ESCC.

\section{Acknowledgements}

Not applicable.

\section{Funding}

This study was supported by the National Science Foundation of China Grants (grant no. 82003048), the Anhui Provincial Natural Science Foundation (grant no. 1908085QC131) and Grants for Scientific Research of BSKY from Anhui Medical University (grant no. XJ201726).

\section{Availability of data and materials}

The datasets used and/or analyzed during the current study are available from the corresponding author on reasonable request.

\section{Authors' contributions}

WH and RZ designed the study. YH, RR and YF performed the experiments. KW, LY and RR analyzed the data. WH and RZ wrote the manuscript. All authors read and approved the final manuscript. WH and RZ confirm the authenticity of all the raw data.

\section{Ethics approval and consent to participate}

The present study was approved by the Ethics Committee of Anhui Medical University (Hefei, China; approval no. 20190356). All patients provided signed informed consent prior to the study.

\section{Patient consent for publication}

Not applicable.

\section{Competing interests}

The authors declare that they have no competing interests. 


\section{References}

1. Torre LA, Bray F, Siegel RL, Ferlay J, Lortet-Tieulent J and Jemal A: Global cancer statistics, 2012. CA Cancer J Clin 65 87-108, 2015.

2. Short MW, Burgers KG and Fry VT: Esophageal cancer. Am Fam Physician 95: 22-28, 2017.

3. Enzinger PC and Mayer RJ: Esophageal cancer. N Engl J Med 349: 2241-2252, 2003

4. Song Y, Li L, Ou Y, Gao Z, Li E, Li X, Zhang W, Wang J, Xu L, Zhou Y, et al: Identification of genomic alterations in oesophageal squamous cell cancer. Nature 509: 91-95, 2014

5. Zhang SW, Zhang M and Li GL: An analysis of incidence and mortality of esophageal cancer in China, 2003-2007. China Cancer 4: 241-247, 2012.

6. Zhang N, Shi J, Shi X, Chen W and Liu J: Mutational characterization and potential prognostic biomarkers of Chinese patients with esophageal squamous cell carcinoma. Onco Targets Ther 13: $12797-12809,2020$

7. Zhong X, Huang G, Ma Q, Liao H, Liu C, Pu W, Xu L, Cai Y and Guo X: Identification of crucial miRNAs and genes in esophageal squamous cell carcinoma by miRNA-mRNA integrated analysis. Medicine (Baltimore) 98: e16269,2019.

8. Liao X, Tang Y, Chattopadhyay SK, Hartley JW and Morse HC III Upregulation of Gfi-1, a gene involved in IL-2-independent growth of $\mathrm{T}$ cells, in a murine retrovirus-induced immunsodeficiency syndrome. In Vivo 11: 9-12, 1997.

9. Cai H, Zhang F and Li Z: Gfi-1 promotes proliferation of human cervical carcinoma via targeting of FBW7 ubiquitin ligase expression. Cancer Manag Res 10: 2849-2857, 2018.

10. Cheng B, Tang S, Zhe N, Ma D, Yu K, Wei D, Zhou Z, Lu T, Wang $J$ and Fang Q: Low expression of GFI-1 gene is associated with panobinostat-resistance in acute myeloid leukemia through influencing the level of HO-1. Biomed Pharmacother 100 509-520, 2018

11. Xian G, Zhao J, Qin C, Zhang Z, Lin Y and Su Z: Simvastatin attenuates macrophage-mediated gemcitabine resistance of pancreatic ductal adenocarcinoma by regulating the TGF- $\beta 1 /$ Gfi- 1 axis. Cancer Lett 385: 65-74, 2017.

12. Lee MC, Kuo YY, Chou WC, Hou HA, Hsiao M and Tien HF: Gfi-1 is the transcriptional repressor of SOCS1 in acute myeloid leukemia cells. J Leukoc Biol 95: 105-115, 2014.

13. Durham GA, Williams JJL, Nasim MT and Palmer TM: Targeting SOCS proteins to control JAK-STAT signalling in disease. Trends Pharmacol Sci 40: 298-308, 2019.

14. Yong YH, Wang P, Jia RM, Gooneratne R, Robert Wang HC, Liao M and Ju XH: SOCS3 control the activity of NF- $\kappa$ B induced by HSP70 via degradation of MyD88-adapter-like protein (Mal) in IPEC-J2 cells. Int J Hyperthermia 36: 151-159, 2019.

15. Liau NPD, Laktyushin A, Lucet IS, Murphy JM, Yao S, Whitlock E, Callaghan K, Nicola NA, Kershaw NJ and Babon JJ: The molecular basis of JAK/STAT inhibition by SOCS1. Nat Commun 9: 1558, 2018.

16. Sugase T, Takahashi T, Serada S, Nakatsuka R, Fujimoto M, Ohkawara T, Hara H, Nishigaki T, Tanaka K, Miyazaki Y, et al: Suppressor of cytokine signaling-1 gene therapy induces potent antitumor effect in patient-derived esophageal squamous cell carcinoma xenograft mice. Int J Cancer 140: 2608-2621, 2017.

17. Sugase T, Takahashi T, Serada S, Fujimoto M, Hiramatsu K, Ohkawara T, Tanaka K, Miyazaki Y,Makino T,Kurokawa Y, et al: SOCS1 gene therapy improves radiosensitivity and enhances irradiation-induced DNA damage in esophageal squamous cell carcinoma. Cancer Res 77: 6975-6986, 2017.

18. Amin MB, Gress DM, Meyer Vega LR, et al: AJCC cancer staging manual. 8th edition. New York, Springer, 2017.

19. Livak KJ and Schmittgen TD: Analysis of relative gene expression data using real-time quantitative PCR and the 2(-Delta Delta C(T)) method. Methods 25: 402-408, 2001

20. Mut M, Amos S and Hussaini IM: PKC alpha phosphorylates cytosolic NF-kappaB/p65 and PKC delta delays nuclear translocation of NF-kappaB/p65 in U1242 glioblastoma cells. Turk Neurosurg 20: 277-285, 2010.

21. Lin HN, Chen LQ, Shang QX, Yuan Y and Yang YS: A meta-analysis on surgery with or without postoperative radiotherapy to treat squamous cell esophageal carcinoma. Int J Surg 80: 184-191, 2020

22. Reichenbach ZW, Murray MG, Saxena R, Farkas D, Karassik EG Klochkova A, Patel K, Tice C, Hall TM, Gang J, et al: Clinical and translational advances in esophageal squamous cell carcinoma. Adv Cancer Res 144: 95-135, 2019.
23. Chen J, Yin W, Yao H and Gu W: Salvage treatment for lymph node recurrence after radical resection of esophageal squamous cell carcinoma. Radiat Oncol 14: 169, 2019.

24. Duan $Z$ and Horwitz M: Targets of the transcriptional repressor oncoprotein Gfi-1. Proc Natl Acad Sci USA 100: 5932-5937, 2003

25. Hock H, Hamblen MJ, Rooke HM, Traver D, Bronson RT, Cameron S and Orkin SH: Intrinsic requirement for zinc finger transcription factor Gfi-1 in neutrophil differentiation. Immunity 18: 109-120, 2003.

26. Möröy T and Khandanpour C: Growth factor independence 1 (Gfil) as a regulator of lymphocyte development and activation. Semin Immunol 23: 368-378, 2011.

27. Grimes HL, Gilks CB, Chan TO, Porter S and Tsichlis PN: The Gfi-1 protooncoprotein represses Bax expression and inhibits T-cell death. Proc Natl Acad Sci USA 93: 14569-14573, 1996.

28. Lin Z, Jiang $\mathbf{J}$ and Liu XS: Ursolic acid-mediated apoptosis of K562 cells involves Stat5/Akt pathway inhibition through the induction of Gfi-1. Sci Rep 6: 33358, 2016.

29. Soliera AR, Mariani SA, Audia A, Lidonnici MR, Addya S, Ferrari-Amorotti G, Cattelani S, Manzotti G, Fragliasso V, Peterson L, et al: Gfi-1 inhibits proliferation and colony formation of $\mathrm{p} 210 \mathrm{BCR} / \mathrm{ABL}$-expressing cells via transcriptional repression of STAT 5 and Mcl-1. Leukemia 26: 1555-1563, 2012.

30. Yoshimura A, Naka T and Kubo M: SOCS proteins, cytokine signalling and immune regulation. Nat Rev Immunol 7: 454-465, 2007.

31. Sharma J and Larkin J III: Therapeutic implication of SOCS1 modulation in the treatment of autoimmunity and cancer. Front Pharmacol 10: 324, 2019.

32. Chen Q, Yin D, Zhang Y, Yu L, Li XD, Zhou ZJ, Zhou SL, Gao DM, Hu J, Jin C, et al: MicroRNA-29a induces loss of 5-hydroxymethylcytosine and promotes metastasis of hepatocellular carcinoma through a TET-SOCS1-MMP9 signaling axis. Cell Death Dis 8: e2906, 2017.

33. Demirel I, Säve S, Kruse R and Persson K: Expression of suppressor of cytokine signalling 3 (SOCS3) in human bladder epithelial cells infected with uropathogenic Escherichia coli. APMIS 121: 158-167, 2013

34. Qian Q, Lv Y and Li P: SOCS1 is associated with clinical progression and acts as an oncogenic role in triple-negative breast cancer. IUBMB Life 70: 320-327, 2018.

35. Gong HL, Tao Y, Mao XZ, Song DY, You D and Ni JD: MicroRNA-29a suppresses the invasion and migration of osteosarcoma cells by regulating the SOCS1/NF- $\kappa \mathrm{B}$ signalling pathway through negatively targeting DNMT3B. Int J Mo Med 44: 1219-1232, 2019.

36. Souma Y, Nishida T, Serada S, Iwahori K, Takahashi T, Fujimoto M, Ripley B, Nakajima K, Miyazaki Y, Mori M, et al: Antiproliferative effect of SOCS-1 through the suppression of STAT3 and p38 MAPK activation in gastric cancer cells. Int J Cancer 131: 1287-1296, 2012.

37. Chun KS, Jang JH and Kim DH: Perspectives regarding the intersections between STAT3 and oxidative metabolism in cancer. Cells 9: 2202, 2020

38. Rasmi RR, Sakthivel KM and Guruvayoorappan C: NF- $\kappa$ B inhibitors in treatment and prevention of lung cancer. Biomed Pharmacother 130: 110569, 2020.

39. Zhao J, Wang X, Mi Z, Jiang X, Sun L, Zheng B, Wang J, Meng M, Zhang L, Wang Z, et al: STAT3/miR-135b/NF- $\kappa$ B axis confers aggressiveness and unfavorable prognosis in non-small-cell lung cancer. Cell Death Dis 12: 493, 2021.

40. Cong Y, Cui Y, Zhu S, Cao J, Zou H, Martin TA, Qiao G, Jiang W and Yu Z: Tim-3 promotes cell aggressiveness and paclitaxel resistance through $\mathrm{NF}-\kappa \mathrm{B} / \mathrm{STAT} 3$ signalling pathway in breast cancer cells. Chin J Cancer Res 32: 564-579, 2020.

41. Ma J, Yang Y, Fu Y, Guo F, Zhang X, Xiao S, Zhu W, Huang Z, Zhang J and Chen J: PIAS3-mediated feedback loops promote chronic colitis-associated malignant transformation. Theranostics 8: 3022-3037, 2018.

42. Long L, Pang XX, Lei F, Zhang JS, Wang W, Liao LD, Xu XE, He JZ, Wu JY, Wu ZY, et al: SLC52A3 expression is activated by $\mathrm{NF}-\kappa \mathrm{B}$ p65/Rel-B and serves as a prognostic biomarker in esophageal cancer. Cell Mol Life Sci 75: 2643-2661, 2018.

43. Liu Y, Wang X, Zeng S, Zhang X, Zhao J, Zhang X, Chen X, Yang W, Yang Y, Dong Z, et al: The natural polyphenol curcumin induces apoptosis by suppressing STAT3 signaling in esophageal squamous cell carcinoma. J Exp Clin Cancer Res 37: 303, 2018.

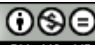

This work is licensed under a Creative Commons Attribution-NonCommercial-NoDerivatives 4.0 International (CC BY-NC-ND 4.0) License. 